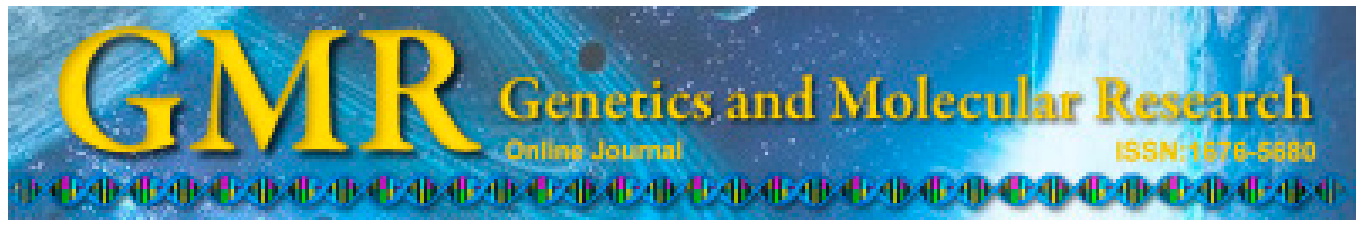

\title{
Development of novel polymorphic microsatellite markers for the silver fox (Vulpes vulpes)
}

S.Q. Yan ${ }^{1}$, C.Y. Bai ${ }^{1}$, S.M. Qi ${ }^{2}$, Y.M. Li ${ }^{1}$, W.J. Li ${ }^{1}$ and J.H. Sun ${ }^{2}$

${ }^{1}$ College of Animal Science, Jilin University, Changchun, China

${ }^{2}$ College of Animal Science and Veterinary Medicine,

Qingdao Agricultural University, Qingdao, China

Corresponding authors: S.Q. Yan / J.H. Sun

E-mail: yansq@jlu.edu.cn / jhsun0528@163.com

Genet. Mol. Res. 14 (2): 5890-5895 (2015)

Received July 21, 2014

Accepted January 21, 2015

Published June 1, 2015

DOI http://dx.doi.org/10.4238/2015.June.1.6

ABSTRACT. The silver fox (Vulpes vulpes), a coat color variant of
the red fox, is one of the most important fur-bearing animals. To date,
development of microsatellite loci for the silver fox has been limited
and mainly based on cross-amplification by using canine SSR primers.
In this study, 28 polymorphic microsatellite markers were isolated and
identified for silver fox through the construction and screening of an
(AC) -enriched library. The number of alleles per locus ranged from 2
to 8 based on 48 individuals tested. The expected and observed hetero- 
zygosity and polymorphism information content per locus ranged from 0.2544 to $0.859,0.2083$ to 0.7917 , and 0.2181 to 0.821 , respectively. The polymorphic markers presented in this study may be useful for future analysis of the genetic diversity and population structure of farmed silver fox and wild red fox.

Key words: Silver fox; Microsatellite marker; Genetic polymorphism

\section{INTRODUCTION}

The red fox (Vulpes vulpes) belongs to the Canidae family and is the most widely distributed terrestrial carnivore in the world (Larivière and Pasitschniak-Arts, 1996). The silver fox, a farmed coat color variant of the red fox, has been domesticated for animal behavioral studies (Statham et al., 2011; Kukekova et al., 2012) and raised to provide fur for the clothing industry (Nowacka-Woszuk et al., 2013).

Microsatellites, also known as simple sequence repeats (SSRs), are short tandem repeats 1-6 bp in length (Zhao and Kochert, 1993). Microsatellite markers have been widely used in population genetic analysis due to their high degree of polymorphism, co-dominance, and their abundance in the eukaryotic genome (Sha et al., 2009; Ma and Chen, 2011). To date, development of microsatellite loci for the silver fox has been very limited and mainly based on cross-species amplification with canine SSR primers (Kukekova et al., 2004; Sacks and Louie, 2008). In the present study, we developed 28 polymorphic microsatellite markers for silver fox from a microsatellite enriched library.

\section{MATERIAL AND METHODS}

Genomic DNA from the muscle tissue of 48 farmed silver foxes was isolated using the standard proteinase $\mathrm{K} /$ phenol extraction protocol (Sambrook and Russel, 2001). A partial DNA library enriched for (AC) motifs was constructed as described by Novelli et al. (2006) with modifications. Briefly, the genomic DNA from a male individual was digested with the Sau3A I restriction enzyme. Fragments ranging from 300 to $1000 \mathrm{bp}$ were recovered and ligated with adapters (Linker1: 5'-PO -GATCGCAGAATTCGCACGAGTA CTAC-3'; Linker2: 5'-GTAGTACTCGTGCGAATTCTGC-3'). The fragments were enriched by hybridizing to an $(\mathrm{AC})_{13}$ biotin-labeled probe and separated with streptavidin magnetic beads (Promega, Madison, USA). The amplified products from the Linker2 primer were cloned into a pMD18-T vector (Takara, Dalian, China) and transformed into E. coli $\mathrm{DH} 5 \alpha$ competent cells. Clones containing inserts were sequenced by Sangon Biotech (Shanghai, China).

Primer pairs were designed according to the flanking DNA sequences of the repetitive region using Primer Premier 5.0 (Premier Biosoft International, Palo Alto, CA, USA). A M13 (-21) tail (5'-TGTAAAACGACGGCCAGT-3') was added to all the for- 
ward primers (Schuelke, 2000). The universal M13 (-21) primer was fluorescently labeled (FAM, HEX, or TAMARD). To evaluate the PCR primers and amplification conditions, preliminary analyses were first conducted with a sample of 4 individuals. The polymorphic information for those loci that showed specific amplification patterns was assessed in 48 farmed silver foxes following the protocol provided by Schuelke (2000) with modifications. PCR was conducted in a total reaction volume of $25 \mu \mathrm{L}$ containing approximately 10 ng genomic DNA, 1X Taq polymerase buffer with $\mathrm{Mg}^{2+}, 0.1 \mathrm{mM}$ of each dNTP, $0.5 \mathrm{U}$ Taq polymerase (Takara), $0.25 \mu \mathrm{M}$ M13 (-21) tailed forward primer, $1 \mu \mathrm{M}$ M13 (-21) fluorescently labeled tag primer, and $1 \mu \mathrm{M}$ reverse primer. PCR amplification was conducted on a GeneAmp PCR System 9700 (Applied Biosystems, Foster City, CA, USA) with the following condition: $95^{\circ} \mathrm{C}$ for $3 \mathrm{~min}$, followed by 30 cycles of $94^{\circ} \mathrm{C}$ for $30 \mathrm{~s}, 58^{\circ} \mathrm{C}$ for 30 $\mathrm{s}$, and $72^{\circ} \mathrm{C}$ for $30 \mathrm{~s}$, and a final extension at $72^{\circ} \mathrm{C}$ for $20 \mathrm{~min}$.

The fluorescently labeled products were separated on an ABI 3730 DNA sequencer in conjunction with the GeneScan-500 internal size standard (Applied Biosystems). Allele size was estimated using the GeneMapper ${ }^{\circledR}$ software version 4.0 (Applied Biosystems). The polymorphic parameters for each locus, including number of alleles, observed heterozygosity $\left(H_{\mathrm{O}}\right)$, expected heterozygosity $\left(H_{\mathrm{E}}\right)$ and the polymorphism information content (PIC), were assessed using the CERVUS 2.0 software (Marshall et al., 1998). Deviations from Hardy-Weinberg equilibrium were evaluated using the GENEPOP software (Raymond and Rousset, 1995).

\section{RESULTS AND DISCUSSION}

Sequencing analysis revealed that out of 142 recombinant clones, 113 clones contained more than five CA or TG tandem repeats. Each colony was given a name consisting of the prefix VVM ( $V$. vulpes microsatellite) followed by a number. The number of CA or TG repeats in these clones ranged from 4 to 20 . Of the 113 clones, 78 had perfect motifs, 20 had imperfect motifs, and 15 had compound repeat motifs.

Fifty-eight primer sets were designed for microsatellite sequences, which contained at least 8 repeats and possessed sufficient flanking sequences suitable for primer design. Thirty-three loci produced specific products while other primers showed multibanded patterns or non-specific amplification. Of these 33 loci, 28 exhibited polymorphisms in the 48 individuals tested. The primer sequences, motif information, number of alleles, PCR product size, and the GenBank accession No. of the 28 loci are shown in Table 1. The number of alleles per locus ranged from 2 to 8 . The $H_{\mathrm{E}}$ and $H_{\mathrm{O}}$ per locus ranged from 0.2544 to 0.859 with a mean of 0.6371 and from 0.2083 to 0.7917 with a mean of 0.5856 , respectively. The PIC ranged from 0.2181 to 0.821 with a mean of 0.5683 . None of the loci showed significant deviations from Hardy-Weinberg equilibrium in the population tested.

In summary, the 28 polymorphic microsatellite loci described in the present study will provide useful tools to estimate the population genetic structure and diversity of the farmed silver fox and wild red fox in the future. 


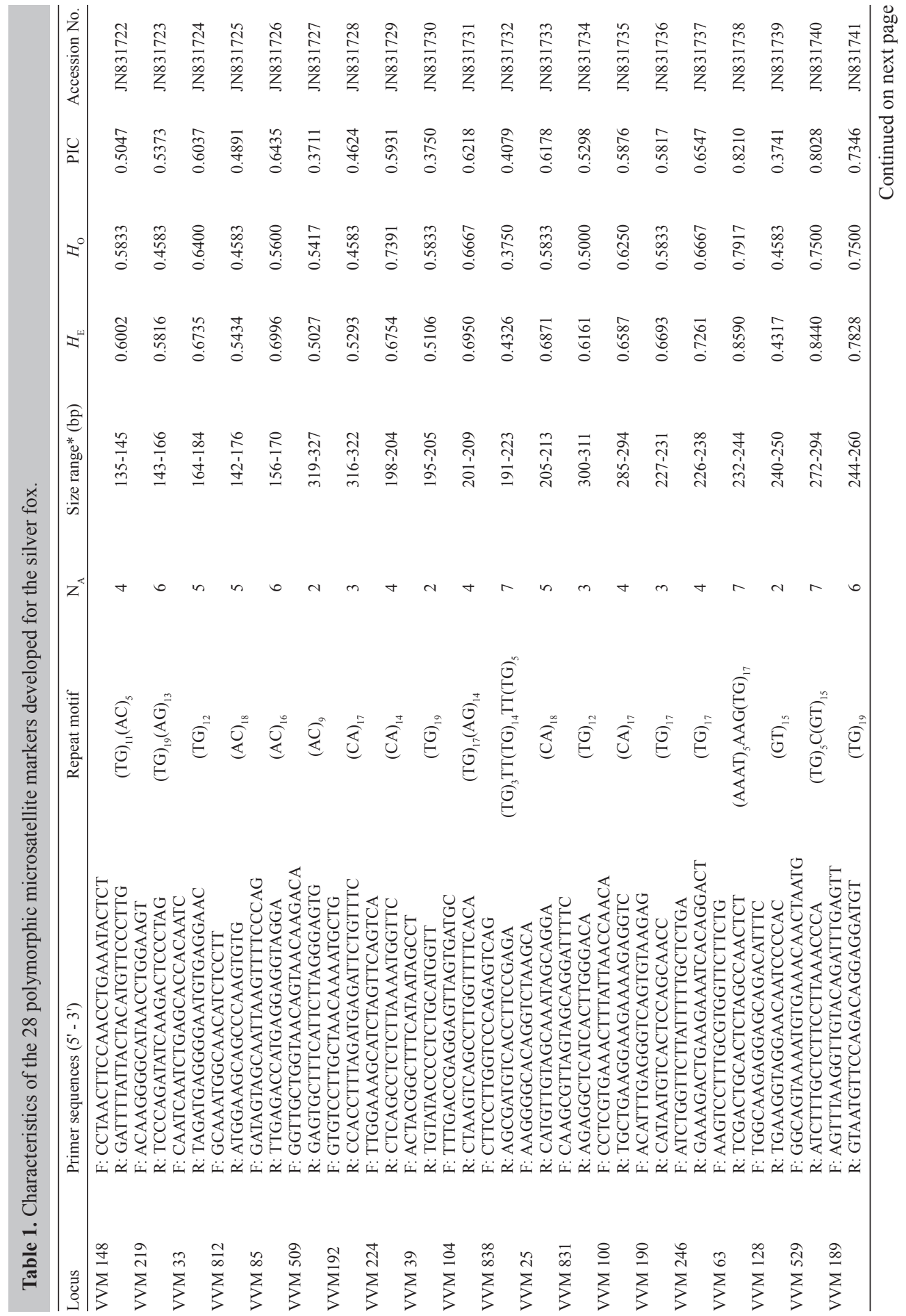




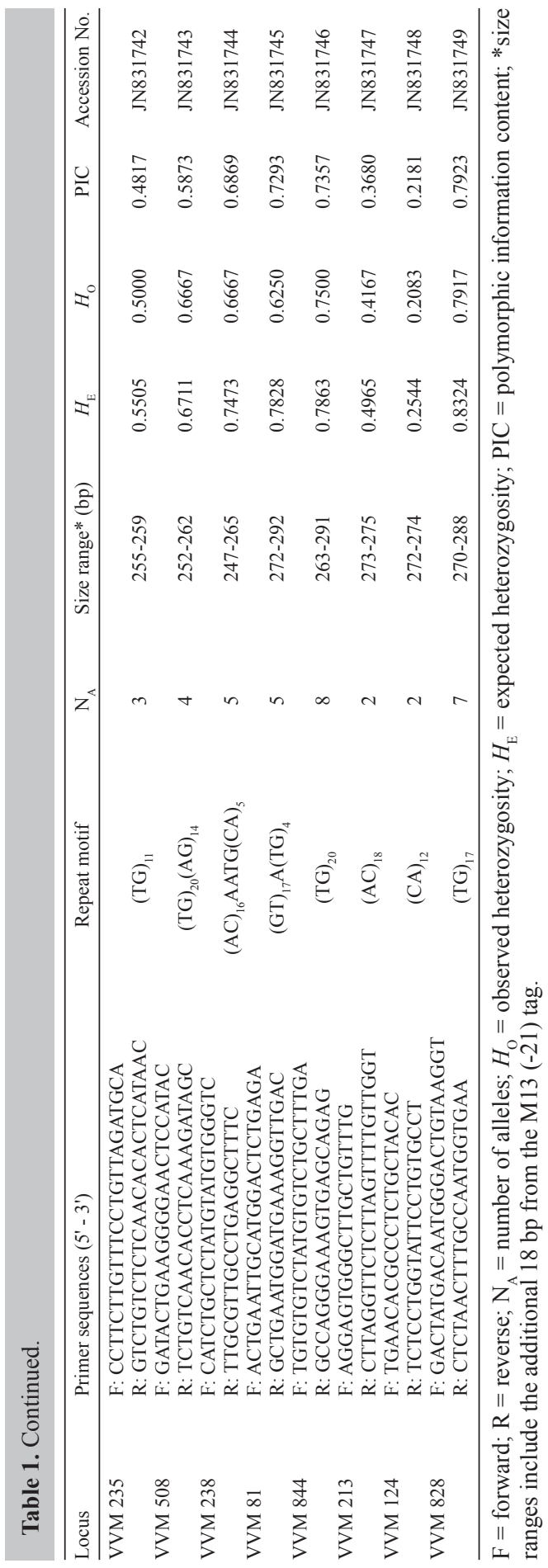




\title{
ACKNOWLEDGMENTS
}

\author{
(\#31072018). \\ Research supported by projects of the National Natural Science Foundation of China
}

\section{REFERENCES}

Kukekova AV, Trut LN, Oskina IN, Kharlamova AV, et al. (2004). A marker set for construction of a genetic map of the silver fox (Vulpes vulpes). J. Hered. 95: 185-194.

Kukekova AV, Temnykh SV, Johnson JL, Trut LN, et al. (2012). Genetics of behavior in the silver fox. Mamm. Genome 23: $164-177$.

Larivière S and Pasitschniak-Arts M (1996). Vulpes vulpes. Mamm. Species 537: 1-11.

Ma H and Chen S (2011). Development of polymorphic microsatellite markers in barfin flounder (Verasper moseri) and spotted halibut (Verasper variegatus) by the cross-species amplification. Mol. Biol. Rep. 38: 4545-4551.

Marshall TC, Slate J, Kruuk LE and Pemberton JM (1998). Statistical confidence for likelihood-based paternity inference in natural populations. Mol. Ecol. 7: 639-655.

Novelli VM, Cristofani M, Souza AA and Machado MA (2006). Development and characterization of polymorphic microsatellite markers for the sweet orange (Citrus sinensis L. Osbeck). Genet. Mol. Biol. 29: 90-96.

Nowacka-Woszuk J, Salamon S, Gorna A and Switonski M (2013). Missense polymorphisms in the MC1R gene of the dog, red fox, arctic fox and Chinese raccoon dog. J. Anim. Breed. Genet. 130: 136-141.

Raymond M and Rousset F (1995). GENEPOP (version 1.2): population genetics software for exact tests and ecumenicism. J. Hered. 86: 248-249.

Sacks BN and Louie S (2008). Using the dog genome to find single nucleotide polymorphisms in red foxes and other distantly related members of the Canidae. Mol. Ecol. Resour. 8: 35-49.

Sambrook J and Russel D (2001). Molecular cloning. Cold Spring Harbor Laboratory Press, New York.

Sha ZX, Xing SC, Shao CW, Tian YS, et al. (2009). Isolation and characterization of 12 polymorphic microsatellite markers from ladyfish (Elops saurus Linnaeus). Conserv. Genet. 10: 1799-1801.

Schuelke M (2000). An economic method for the fluorescent labeling of PCR fragments. Nat. Biotechnol. 18: $233-234$.

Statham MJ, Trut LN, Sacks BN, Kharlamova AV, et al. (2011). On the origin of a domesticated species: identifying the parent population of Russian silver foxes (Vulpes vulpes). Biol. J. Linn. Soc. Lond. 103: 168-175.

Zhao X and Kochert G (1993). Phylogenetic distribution and genetic mapping of a (GGC) microsatellite from rice (Oryza sativa L.). Plant Mol. Biol. 21: 607-614. 